\title{
Childhood Nasal Foreign Bodies: Analysis of 1724 Cases
}

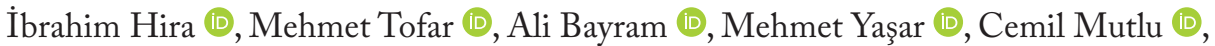 \\ İbrahim Özcan (D) \\ Original Investigation D Department of Otorhinolaryngology Head and Neck Surgery, Health Science University Kayseri Training and Research Hospital, \\ Kayseri, Turkey
}

Abstract

ORCID IDs of the authors: i.H. 0000-0002-1654-8690; M.T. 0000-0001-9017-6023; A.B. 0000-0001-7311-8358; M.Y. 0000-0002-2758-3635; C.M. 0000-0003-3585-6549; 1.0. 0000-0002-4359-2988

Cite this article as: Hira I, Tofar M, Bayram A, Yaşar M, Mutlu C, Özcan I. Childhood Nasal Foreign Bodies: Analysis of 1724 Cases. Turk Arch Otorhinolaryngol 2019; 57(4): 187-90.

This study was presented at the $40^{\text {th }}$ Turkish National Congress of Otorhinolaryngology Head and Neck Surgery, November 7-11, 2018, Antalya, Turkey.

Corresponding Author: İbrahim Hira; dr.ibrahimhira@gmail.com

Received Date: 21.01.2019 Accepted Date: 28.04.2019

Content of this journal is licensed under a Creative Commons Attribution 4.0 International License. Available online at www.turkarchotolaryngol.net
Objective: This study evaluates the characteristics of the foreign bodies removed from the nose, the treatment methods used, and the complications associated with the foreign body, and discusses the reports in the literature.

Methods: Age, gender, type of foreign body, side of nose, clinical symptoms, complaints, diagnosis and treatment methods were retrospectively evaluated in all 1724 pediatric patients with foreign bodies.

Results: Of the 1724 patients, 841 (48.7\%) were female and 883 (51.3\%) were male. Their mean age was $4.3 \pm 3.06$ years (age range: 4 months -16 years). Foreign body was found on the right side in 928 (53.8\%), on the left-side in $768(44.5 \%)$ and bilaterally in 28 (1.6\%) patients. The foreign bodies were inorganic substances such as beads, paper, napkins, toy parts, batteries, pencils, erasers in 1287 cases (74.7\%) and organic materials such as hazelnuts, walnuts and fruit seeds in 437 cases (25.3\%). The foreign bodies were extracted in outpatient settings in 1709 cases. Fifteen patients in whom the foreign body was located in the posterior region and/or who were uncooperative were treated under anesthesia. The most common complication was epistaxis. Septal perforation was seen in one patient with alkaline battery.

Conclusion: In pediatric patients presented to the otolaryngology and the pediatrics clinics with complaints involving nasal obstruction, unilateral purulent nasal discharge, epistaxis, and foul odor, possibility of a foreign body in the nose should be kept in mind.

Keywords: Nose, childhood, pediatrics, foreign body

\section{Introduction}

Nasal foreign bodies constitute an emergency of the ear, nose, and throat (ENT) and are more common in children (1). Nasal foreign bodies may also be life-threatening in case of aspiration. According to various studies, nasal foreign bodies account for $19-49 \%$ of the foreign bodies encountered in ENT clinics (2). Many cases are detected incidentally during the examination of patients with nasal obstruction, unilateral nasal discharge, and epistaxis. Foreign objects retained for a long time may present with complications such as sinusitis, otitis, meningitis. Therefore, in patients with unilateral purulent nasal discharge, epistaxis, and foul odor in the nose, the presence of nasal foreign bodies should always be suspected (3). Foreign bodies can usually be removed in outpatient settings; however, anesthesia may be needed depending on their location and the patient's cooperativeness.

In this study, 1724 patients with nasal foreign bodies were evaluated and compared with those reported in the literature in terms of demographic characteristics, diagnosis, treatment, and complications.

\section{Methods}

The study was approved by the local Ethics Committee of University of Health Sciences, Kayseri Training and Research Hospital (Approval Date: 20 March 2018; No: 52332816/13) and conducted in accordance to the Declaration of Helsinki. It was designed as a retrospective cohort study; thus, no written informed consent was obtained from the patients. 


\section{Study subjects}

This retrospective study was conducted at a tertiary care hospital. We retrospectively analyzed 1724 patients who presented to the ENT clinic and had foreign bodies removed from their nose in the period from January 2014 through December 2017. The age, gender, type of foreign body, side of nose, clinical symptoms, complaints (epistaxis, unilateral purulent nasal discharge or nasal congestion, foul odor, etc.) were evaluated from the patient records retrospectively.

\section{Statistical Analysis}

All statistical analyses were performed using the Statistical Package for the Social Sciences version 12.0, (SPSS Inc., Chicago, IL, USA) statistics software. Continuous variables were expressed as mean values \pm standard deviation. Categorical variables were expressed as numbers and percentage.

\section{Results}

We retrospectively evaluated the data from 1724 pediatric patients with foreign bodies. All patients routinely underwent an anterior rhinoscopic examination with a nasal speculum and additional endoscopic nasal examination was performed in cases in which the foreign bodies could not be visualized. Of the $1724 \mathrm{pa}^{-}$ tients, $841(48.7 \%)$ were female and $883(51.3 \%)$ were male. Their mean age was $4.3 \pm 3.06$ years (age range: 4 months- 16 years). In 431 (25\%) of the cases, the family noticed the incident and consulted a doctor. Other reasons for referral to the ENT clinic were self-report of child, nasal congestion, bleeding, and foul odor. The foreign body was located on the right-side in 928 (53.8\%), on the left-side in 768 (44.5\%) and bilaterally in 28 (1.6\%) patients (Figure 1$)$. When the age distribution was assessed, $36 \%$ of the cases (623 cases) were between 2 and 5 years of age (Table 1).

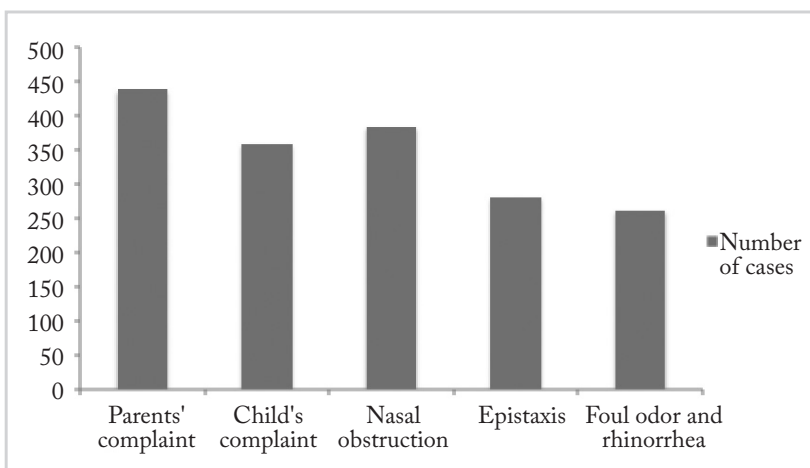

Figure 1. Evaluation of symptoms and complaints of patients
The extracted foreign bodies consisted of both organic and inorganic substances. Inorganic substances such as beads, paper, napkins, toy parts, batteries, pencils, erasers were extracted in 1287 cases $(74.7 \%)$, whereas organic materials such as hazelnuts, walnuts and fruit seeds in 437 cases (25.3\%) (Table 1). More than one foreign body were extracted in 24 cases. In most of the cases (1709 cases, 99.1\%), foreign bodies were situated in the anterior part of the nasal cavity, between the inferior turbinate and the septum, or in other words, not posterior to the middle turbinate alignment. The foreign bodies with anterior localization were removed in the examination room with the help of a speculum, a suction device, a foreign body curette, and forceps. In 15 cases, because of the posterior location of the foreign body, and/or the patient's inability to cooperate, the patient was treated under sedation in the operating room. In addition, the foreign body was removed after oro-tracheal intubation due to the risk of aspiration in three of these patients.

The most common complication after foreign body extraction was epistaxis. This complication was seen more commonly especially in patients with hard and irregularly shaped foreign bodies such as a plastic toy part or a stone. None of these patients had any bleeding that required nasal packing. Septal perforation was found in one patient who had an alkaline battery. Despite the presence of intense mucosal necrosis, cartilage necrosis did not develop in the other patients in whom batteries were extracted. Antimicrobial and nasal douche with isotonic saline solution were recommended to the patients with mucosal injury. No additional complications such as synechiae were observed during the postoperative follow-up period.

\section{Discussion}

Nasal foreign bodies are usually seen in early childhood $(1,2)$. While a cause of substantial panic in the family, nasal foreign bodies can lead to various complications, but not to a life-threatening condition in general (2). However, the risks of aspiration should be kept in mind in cases of foreign bodies, especially in those located in the posterior region. Such cases are also very common and have an important role in the ENT practice. For example, in a study examining the foreign bodies in the ear, the nose, and the throat by Mukherjee et al. (3), foreign bodies were reported to be most often seen in the nose (44\%).

Nasal foreign bodies are usually seen in the first decade when the child starts moving and playing and attempts to know the

Table 1. Classification of foreign bodies by age groups of patients and types of foreign body

\begin{tabular}{|c|c|c|c|c|c|}
\hline Foreign body & Age $0-2$ yrs (n) & Age 2-5 yrs (n) & Age 5-10 yrs (n) & Age $\geq 10$ yrs (n) & Total (n, \%) \\
\hline Paper, napkin, sponge & 116 & 177 & 125 & 65 & $483(28.0)$ \\
\hline Plastic button, bead, toy, stone & 163 & 188 & 83 & 28 & $462(26.7)$ \\
\hline Hazelnut, walnut, fruit seed & 134 & 118 & 133 & 52 & $437(25.3)$ \\
\hline Pen, paint, eraser & 31 & 138 & 133 & 34 & $336(19.4)$ \\
\hline Battery & - & 2 & 4 & - & $6(0.3)$ \\
\hline Total (n) & 444 & 623 & 478 & 179 & 1724 \\
\hline
\end{tabular}


environment. It is less common after 10 years of age. In our study, $61.8 \%$ of the cases were within the first 5 years of age and $89.7 \%$ within the first 10 years of age. In adulthood it is more often seen in adults with mental problems (1). Genderwise, it is more common among boys (3). In our study, male patients constituted more than half of this series and this was found consistent with the literature. It has been previously reported that foreign bodies are more common on the right side because most patients $(51.3 \%)$ are right-handed $(4,5)$. We found a foreign body in the right nostril in 928 (53.8\%), in the left nostril in $768(44.5 \%)$ and in both nostrils in 28 (1.6\%) of the patients.

Nasal foreign bodies, in general, do not cause pain and can remain in the nose without being noticed for a long time. However, nasal congestion, unilateral purulent nasal discharge, epistaxis, foul odor can be the presenting symptoms (6). A child with unilateral purulent nasal discharge should be examined for the possibility of a foreign body. Also, a study by Chiun et al. (7) reported that $75 \%$ of the cases presented to the emergency department were self-reporting cases that they inserted a foreign body into their nose. In our study, $25 \%$ of the cases were noticed by the family and $20 \%$ of the cases were directly consulted to a doctor with a complaint of a foreign body following the child's report. Other patients presented with nasal obstruction, discharge, foul odor. None of the foreign bodies were incidentally detected (Figure 1).

The types of foreign bodies can be classified as organic and inorganic substances. There are different results in the literature. In a study, Chiun et al. (7) reported the most common foreign bodies as plant seeds and plastic parts. Also, a study by Çelik et al. (8) reported beads and plant parts to be more common in their study population. In our study, soft inorganic foreign bodies (28\%) such as "paper, napkin, sponge" were more common (Table 1).

Successful removal of a nasal foreign body depends on the location of the body, its shape, patient cooperation and the experience of the physician. While interventions are performed in outpatient settings, foreign bodies may migrate to the respiratory tract, especially in young children, and can cause respiratory failure or even death. In their study including 43 pediatric patients, Chiun et al. (7) reported that 53.4\% of their patients underwent an intervention under general anesthesia. In our study, only 15 patients $(0.08 \%)$ underwent sedation and/or general anesthesia. In our clinic, the patients were seated in their parent's lap and kept in a stable position during the intervention. The foreign body was removed with the help of an alligator forceps, and a curette, and an endoscope was used wherever needed. Intervention under sedation, either for the posterior nasal cavity or in patients unable to cooperate, carries the risk of some complications. Anesthesia, however, should also be considered as an additional risk factor. Furthermore, emergency tracheotomy conditions should be provided during the extraction of a foreign body located near the choana.
Nasal foreign bodies can lead to serious infections such as sinusitis, otitis, meningitis (5). Thus, the clinician should not hesitate to perform an endoscopic nasal examination under general anesthesia in case of clinical suspicion. Removing the foreign body as soon as possible will prevent rhinoliths development since the presence of a foreign body can lead to the accumulation of calcium and magnesium salts, and the subsequent formation of rhinoliths by causing chronic inflammation if it remains in the nasal cavity for a prolonged period. Rhinolith development is more commonly seen in objects with an irregular shape and a rough surface (9). The most common complication in our patients was epistaxis, and bleedings were controlled without the need for nasal packing. It is more common with hard and irregular edged bodies. Nasal septum perforation was observed in a patient with alkaline batteries. Necrosis occurs after contact with a chemical substance, such as a battery, in the septal mucosa. Septal perforation, intranasal adhesions, and external nasal deformities may occur (10, 11). Therefore, if chemical containing foreign bodies such as batteries are inserted into the nasal cavity, they should be extracted without delay. Nasal douche and moisturizers should be used to prevent damage to the nasal mucosa. We also started the nasal douche and antibiotics in 6 of our patients with alkaline batteries. We did not find any further complications during the follow-up period of these patients.

\section{Conclusion}

Nasal foreign bodies are common in ENT practice and usually seen in young children. Most common clinical symptoms are nasal obstruction, unilateral purulent nasal discharge, epistaxis and foul odor. If the diagnosis is delayed, we may encounter complications such as sinusitis, otitis media, rhinolith formation, periorbital cellulitis, meningitis. Each patient should be treated individually by selecting an appropriate intervention method in consideration of their cooperation, the properties of the foreign body and the resulting symptoms.

Ethics Committee Approval: Ethics committee approval was received for this study from the local Ethics Committee of University of Health Sciences, Kayseri Training and Research Hospital (Approval Date: 20 March 2018; No: 52332816/13)

Informed Consent: Informed consent was not received due to the retrospective nature of the study.

Peer-review: Externally peer-reviewed.

Author Contributions: Concept - İ.H., M.T., A.B.,M.Y.; Design - İ.H., M.Y., İ.Ö.; Supervision - M.Y., C.M., İ.Ö.; Resource - İ.H., M.T., A.B.; Materials - İ.H., M.T., M.Y.; Data Collection and/or Processing - İ.H., M.T., A.B.; Analysis and/or Interpretation - İ.H., A.B., M.Y.; Literature Search - İ.H., M.Y., C.M.; Writing - İ.H., M.Y.; Critical Reviews - İ.H., A.B., İ.Ö.

Conflict of Interest: The authors declare that they have no conflict of interest.

Financial Disclosure: The authors declared that this study has received no financial support. 


\section{References}

1. Memiş M, İlhan E, Ulucanlı S, Yaman H, Güçlü E. Nasal foreign bodies: an analysis of 130 patients. The Turkish Journal of Ear Nose and Throat 2015; 25: 109-12. [CrossRef]

2. Regonne PE, Ndiaye M, Sy A, Diandy Y, Diop AD, Diallo BK. Nasal foreign bodies in children in a pediatric hospital in Senegal: a three-year assessment. Eur Ann Otorhinolaryngol Head Neck Dis 2017; 134: 361-4. [CrossRef]

3. Mukherjee A, Haldar D, Dutta S, Dutta M, Saha J, Sinha R. Ear, nose and throat foreign bodies in children: a search for socio-demographic correlates. Int J Pediatr Otorhinolaryngol 2011; 75: 510-2. [CrossRef]

4. Leopard DC, Williams RG. Nasal foreign bodies: a sweet experiment. Clin Otolaryngol 2015; 40: 420-1. [CrossRef]

5. Cetinkaya EA, Arslan İB, Cukurova İ. Nasal foreign bodies in children: types, locations, complications and removal. Int J Pediatr Otorhinolaryngol 2015; 79: 1881-5. [CrossRef]
6. Yaroko AA, Baharudin A. Patterns of nasal foreign body in northeast Malaysia: a five-year experience. Eur Ann Otorhinolaryngol Head Neck Dis 2015; 132: 257-9. [CrossRef]

7. Chiun KC, Tang IP, Tan TY, Jong DE. Review of ear, nose and throat foreign bodies in Sarawak General Hospital. A five year experience. Med J Malaysia 2012; 67: 17-20.

8. Çelik M, Olgun B, Altıntaş A, Yegin Y, Kayhan FT. Evaluation of patients with nasal foreign bodies. Haydarpasa Numune Med J 2018; 58: 79-84. [CrossRef]

9. Sakin YF, Gedik M. Rhinolithiasis: Clinic symptoms, diagnosis, treatment options, radiologic findings (Case report). Medeniyet Medical Journal 2009; 24:95-100.

10. Abou-Elfadl M,Horra A, Abada RL, Mahtar M, Roubal M, Kadiri F. Nasal foreign bodies: results of a study of 260 cases. Eur Ann Otorhinolaryngol Head Neck Dis 2015; 132: 343-6. [CrossRef]

11. Endican S, Garap JP, Dubey SP. Ear, nose and throat foreign bodies in Melanesian children: an analysis of 1037 cases. Int J Pediatr Otorhinolaryngol 2006; 70: 1539-45. [CrossRef] 